\title{
On Distances and Measurements
}

This book uses the metric system of distances and measurements: meters instead of feet, kilometers instead of miles, hectares instead of acres. The following list will aid readers not accustomed to these units.

\section{Distance}

- 1 meter $=1.1$ yards or approximately 3.3 feet

To convert meters to yards, divide the number of meters by 0.9144 .

- 1 kilometer $=0.6$ miles

To convert kilometers to miles, multiply the number of kilometers by 0.6 .

- 1 centimeter $=0.4$ inch

To convert centimeters to inches, divide the number of centimeters by 2.54 .

\section{Surface Area}

- 1 hectare $=2.47$ acres

To convert hectares into acres, multiply the number of hectares by 2.471 .

- 1 square kilometer $=0.4$ square miles or 247 acres To convert square kilometers to square miles, multiply the number of square kilometers by 0.386 . 
THIS PAGE INTENTIONALLY LEFT BLANK 